\title{
Microstructural Characterization and Thermal Properties of Aluminium Titanate/Porcelain Ceramic Matrix Composites
}

\author{
M. SACli, U. ONEN*, T. BOYRAZ \\ Cumhuriyet University, Metallurgy and Materials Engineering, Sivas, Türkiye
}

\begin{abstract}
Porcelain represents one of the most complex ceramics, formulated from a mix of clay, feldspar and quartz, sintered at temperatures between $1200{ }^{\circ} \mathrm{C}$ and $1400^{\circ} \mathrm{C}$, to form a glass-ceramic composite. Aluminium titanate $\left(\mathrm{Al}_{2} \mathrm{TiO}_{5}\right)$ exhibits extremely good thermal shock resistance and low thermal conductivity, coupled with good chemical resistance in molten metals. In the present work, aluminium titanate/porcelain ceramics composites with different percentages of $\mathrm{Al}_{2} \mathrm{TiO}_{5}$ was prepared using powder metallurgy techniques. The microstructural, mechanical and thermal properties were characterized using XRD, SEM, dilatometer and a hardness meter. Thermal shock resistance behaviour under water quenching of the as-prepared ceramics was also evaluated. The results have revealed that the addition of aluminium titanate to porcelain matrix improves the properties of the aluminium titanate/porcelain ceramics.
\end{abstract}

DOI: 10.12693/APhysPolA.127.1133

PACS: 81.05.Mh.

\section{Introduction}

Porcelain represents one of the most complex ceramics, formulated from a mix of clay, feldspar and quartz, sintered at temperatures between $1200{ }^{\circ} \mathrm{C}$ and $1400{ }^{\circ} \mathrm{C}$ to form a glass-ceramic composite. The clay is typically comprised of kaolinite, which confers plasticity to green paste and is the precursor of mullite crystals. The fluxing agent is feldspar and the filler is quartz, which most likely leads to higher strengths of the unfired tiles. Firing bodies containing these three components exhibit a grain and bond microstructure, which consists of coarse quartz grains joined by a finer bond or matrix that contains mullite crystals and a glassy phase [1].

Aluminium titanate ceramics $\left(\mathrm{Al}_{2} \mathrm{TiO}_{5}\right)$ is a synthetic ceramic material of potential interest for many structural applications, owing to its high melting point, low thermal conductivity and excellent thermal shock resistance. However, a critical feature, which greatly limits the mechanical properties of polycrystalline $\mathrm{Al}_{2} \mathrm{TiO}_{5}$, is the considerable inter-granular micro cracking, which occurs due to the high thermal anisotropy of individual grains [2]. Aluminium titanate $\left(\mathrm{Al}_{2} \mathrm{TiO}_{5}\right)$, generally obtained by a solid-state reaction between $\mathrm{Al}_{2} \mathrm{O}_{3}$ and $\mathrm{TiO}_{2}$, has a very low thermal expansion coefficient $\left(0.2 \times 10^{-6}\right.$ to $\left.10^{-6}\right)$, low thermal conductivity $\left(0.9 \times 1.5 \mathrm{~W} \mathrm{~m}^{-1} \mathrm{~K}^{-1}\right)$, and a high thermal shock resistance. These properties make it most suitable to be used in components of internal combustion engines, as an insulating coating, electronical and high temperature electrical part components, molten glass and metal thermometer components [3-5].

In this study, binary porcelain-aluminium titanate composites at various compositions were obtained and microstructural, physical, mechanical and thermal properties were characterized.

*corresponding author; e-mail: uonen@cumhuriyet.edu.tr

\section{Experimental}

In this study, porcelain was produced by using kaolin (Eczacıbaşı Esan, Türkiye), quartz (Eczacıbaşı Esan, Türkiye) and potassium feldspar (Eczacıbaşı Esan, Türkiye), powders. The kaolin, quartz and feldspar mixtures, weighed in terms of weight ratio $50 \%$ kaolin, $25 \%$ quartz and $25 \%$ feldspar, were dispersed in water then wet-milled with alumina balls of $10 \mathrm{~mm}$ diameter for 24 hours. Then, $\mathrm{Al}_{2} \mathrm{O}_{3}$ and $\mathrm{TiO}_{2}$ were weighed in mole ratio of 1:1 of aluminium titanate. 1:1 molar ratio mixtures were dispersed in acetone and wet-milled with alumina balls of $10 \mathrm{~mm}$ diameter for $3 \mathrm{~h} . \mathrm{Al}_{2} \mathrm{TiO}_{5}$ ceramics were synthesized by reaction sintering of an equimolar mixture of $\mathrm{Al}_{2} \mathrm{O}_{3}$ and $\mathrm{TiO}_{2}$ powders. The powders were first homogenized by wet ball milling. To obtain aluminium titanate (AT), the resulting mixtures were then sintered at $1600^{\circ} \mathrm{C}$, in air, for $2 \mathrm{~h}$.

Then, additions of aluminium titanate (AT) in weight proportions of $0,10,20$ wt.\% were made to the PAT mixture (hereafter these mixtures are denoted as PAT0, PAT10 and PAT20 respectively). Each lot was again wet mixed according to the procedure described above. Then, mixtures we pressed at $100 \mathrm{MPa}$ into $30 \times 30 \times 5$ $\mathrm{mm}^{3}$ specimens. The compacts were sintered in air, using a heating rate of $5{ }^{\circ} \mathrm{C} \mathrm{min}-1$, at $1350{ }^{\circ} \mathrm{C}$. Bulk density, porosity and water absorption of the sintered samples were measured. Micro hardness (Shimadzu, HMV) was measured on the polished surface of the samples at room temperature. At least six individual tests with a peak load of $2000 \mathrm{~g}$ and a loading time of 20 seconds were performed for each set of composites. Then, the microstructural characterization of the sintered samples was carried out using scanning electron microscopy (Leo 440). The morphological parameters of the various phases were characterized by using a semiautomatic image analyser, EDX. The obtained phases were analysed by X-ray powder diffractometer (Rigaku, Dmax, IIIC) using $\mathrm{Cu} \mathrm{K}_{\alpha}$ radiation. Thermal expansion coefficients were measurement by using dilatometer (Anter,USA). 


\section{Results and discussion}

Table shows physical properties of the sintered PAT ceramics, obtained from the prepared mixtures. Both the bulk and true densities of the composites have decreased with increasing aluminium titanate content. Note that the theoretical density of porcelain is $2.47 \mathrm{~g} \mathrm{~cm}^{-3}$ whereas the density of $\mathrm{Al}_{2} \mathrm{TiO}_{5}$ is $3.20 \mathrm{~g} \mathrm{~cm}^{-3}[4,5]$. It is evident from Table that the porosity and water absorption have decreased with the increasing $\mathrm{Al}_{2} \mathrm{TiO}_{5}$ content (from 0 to $20 \mathrm{wt} . \%$ ) and sintering temperature.

Physical properties of samples sin-

TABLE tered at $1350^{\circ} \mathrm{C}$.

\begin{tabular}{c|c|c|c|c|c}
\hline \hline sample & $\begin{array}{c}\rho_{\text {bulk }} \\
{\left[\mathrm{g} / \mathrm{cm}^{3}\right]}\end{array}$ & $\begin{array}{c}\rho_{\text {true }} \\
{\left[\mathrm{g} / \mathrm{cm}^{3}\right]}\end{array}$ & $\begin{array}{c}\rho_{\text {relative }} \\
{[\%]}\end{array}$ & $\begin{array}{c}\text { porosity } \\
{[\%]}\end{array}$ & $\begin{array}{c}\text { w.abs. } \\
{[\%]}\end{array}$ \\
\hline PAT0 & 1.95 & 2.47 & 78.95 & 21.05 & 0.7 \\
PAT10 & 2.15 & 2.54 & 84.65 & 15.35 & 0.02 \\
PAT20 & 2.24 & 2.62 & 85.50 & 14.50 & 0
\end{tabular}

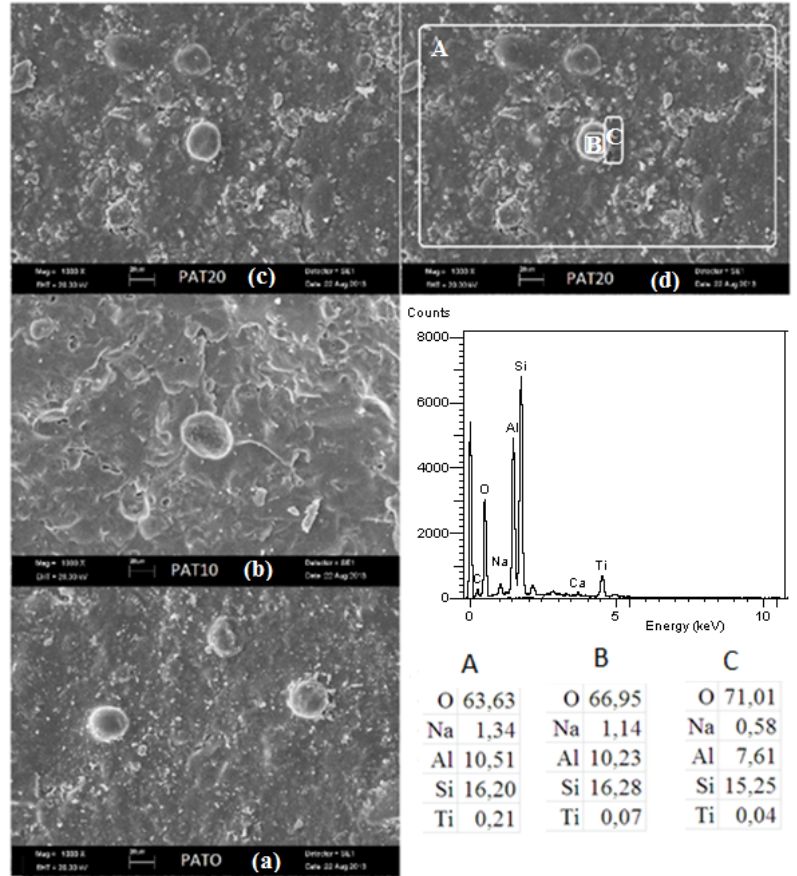

Fig. 1. SEM photomicrographs of (a) PAT0, (b) PAT10, (c) PAT20. (d) Regions of EDX analysis of PAT20 sample.

Figure 1 shows SEM micrographs taken from the surface of the sintered PAT0, PAT10 and PAT20 samples. It can be seen that PAT20 appears to be denser and to have fewer pores than the sample PAT10. Sample PAT10 appears to be denser and to have fewer pores than the sample PAT0. Aluminum titanate is uniformly dispersed in the porcelain matrix. Thus, a denser structure is observed with the increasing aluminium titanate content. The addition of aluminium titanate also influences the grain morphology, as can be seen in the microstructures of the composites. The grain size grows, as the amount of aluminium titanate increases.
Figure 1d shows the microstructure of PAT20 sample used for phase analysis with EDS. Analysis has revealed that the matrix consists of mullite, cristobalite and aluminum titanate phases: the $\mathrm{A}, \mathrm{B}$ and $\mathrm{C}$ areas demonstrated porcelain and aluminum titanate, which consist of $\mathrm{Na}, \mathrm{Al}, \mathrm{Si}, \mathrm{O}$ and $\mathrm{Ti}$.

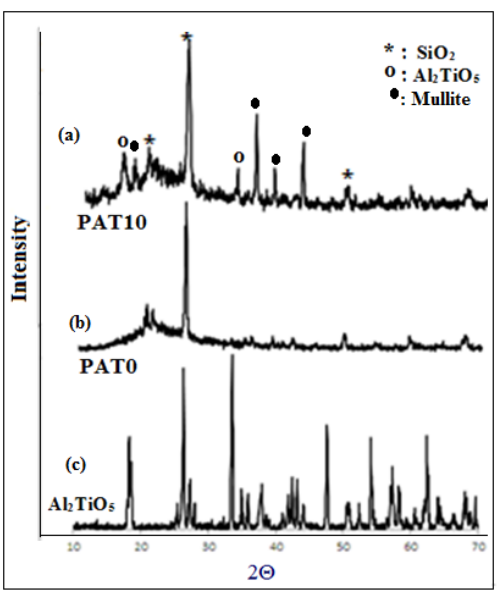

Fig. 2. X-ray diffraction patterns between $10^{\circ}$ and $70^{\circ}$ for samples PAT20 (a), PAT0 (b), aluminium titanate (c). Phases are marked by the following symbols: *: $\mathrm{SiO}_{2}, \circ: \mathrm{Al}_{2} \mathrm{TiO}_{5}$ and $\bullet$ : aluminium titanate.

The X-ray diffraction patterns of the sintered samples are shown in Fig 2. XRD analysis of the as-sintered samples revealed that main phases are $\mathrm{SiO}_{2}$, mullite $\left(2 \mathrm{SiO}_{2} \cdot 3 \mathrm{Al}_{2} \mathrm{O}_{3}\right)$ and aluminum titanate $\left(\mathrm{Al}_{2} \mathrm{TiO}_{5}\right)$ [6].

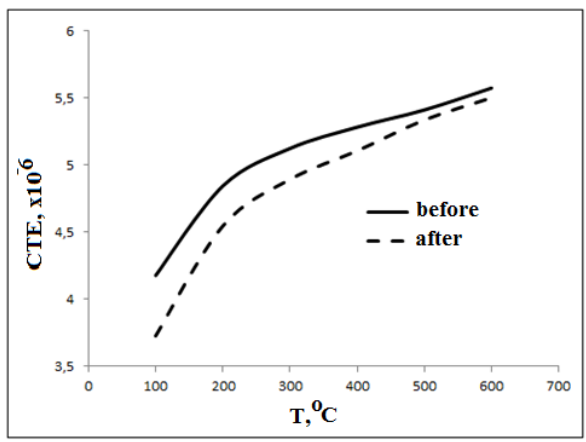

Fig. 3. Plots of average coefficients of thermal expansion of PAT10 ceramics.

The thermal expansion behaviour of PAT10 is shown in Fig. 3. Porcelain has a coefficient of thermal expansion (CTE) of $4.00 \times 10^{-6}{ }^{\circ} \mathrm{C}^{-1}$ in the range $25-1000^{\circ} \mathrm{C}$ [6]. $\mathrm{Al}_{2} \mathrm{TiO}_{5}$ has a coefficient of thermal expansion (CTE) of $1 \times 10^{-6}{ }^{\circ} \mathrm{C}^{-1}$. Addition of AT is observed to decrease the CTE of samples. Samples PAT0 and PAT10 have CTE of $4.177 \times 10^{-6 \circ} \mathrm{C}^{-1}$ and $3.7308 \times 10^{-6}{ }^{\circ} \mathrm{C}^{-1}$, respectively, in the range between $25-1000^{\circ} \mathrm{C}$. It is well known that a low $\mathrm{CTE}$ is one of the requirements for improving thermal shock resistance at elevated temperatures.

Figure 4 shows micro hardness of PAT0, PAT10 and PAT20 samples before and after thermal shock testing. Micro hardness (Shimadzu, HMV) was measured on the polished surface of the samples at room temperature. At 


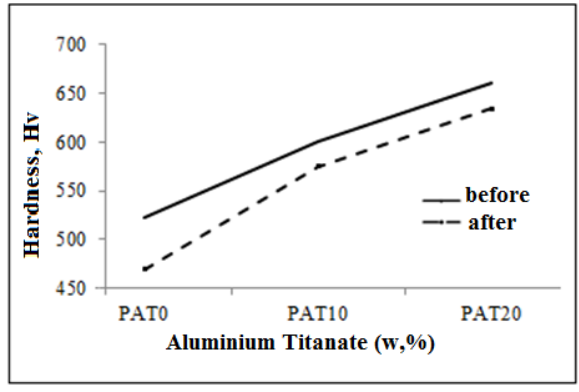

Fig. 4. Vickers micro hardness of PAT0, PAT10 and PAT20 samples before and after the thermal shock testing.

least six individual tests with a peak load of $2000 \mathrm{~g}$ and a loading time of $20 \mathrm{~s}$ were performed for each set of composites. After thermal shock testing, micro hardness was measured again. The micro hardness increases with the increasing AT content. In the case of PAT20, the hardness has the biggest value $(661 \mathrm{Hv})$. Therefore, the increase of AT content can be beneficial for such mechanical properties, like hardness.

\section{Conclusions}

Aluminium titanate/porcelain ceramics with different percentages of $\mathrm{Al}_{2} \mathrm{TiO}_{5}$ was prepared. Microstructural and thermal properties were characterized. A denser structure with fewer pores was observed with the increasing aluminium titanate content. The addition of aluminium titanate also influences the grain morphology, which is observed in the microstructure of the composites. The grain size is growing as the amount of aluminium titanate increases. Porcelain-AT ceramic composites show an increased hardness, which depends on the AT content. Finally, the hardness increases with the increasing content of aluminium titanate. Pure sample has a hardness of $522 \mathrm{Hv}$. The hardness increases to $661 \mathrm{Hv}$ on addition of $20 \mathrm{wt} . \%$ of AT. XRD analysis of the sintered samples has revealed, that main phases in the samples are porcelain and aluminium titanate $\left(\mathrm{Al}_{2} \mathrm{TiO}_{5}\right)$. The CTE of the porcelain has decreased as AT was added to it. Samples PAT0 and PAT20 have CTE of $4.177 \times 10^{-6}{ }^{\circ} \mathrm{C}^{-1}$ and $3.7308 \times 10^{-6}{ }^{\circ} \mathrm{C}^{-1}$, respectively, in the range $25-1000^{\circ} \mathrm{C}$. It is well known that a low CTE is one of the requirements for improving thermal shock resistance at elevated temperatures.

\section{References}

[1] J.M. Pérez, M. Romeron, Ceramics International 40, 1365 (2014)

[2] H.A.J. Thomas, R. Stevens, Br. Ceram. Trans. J. 88, 184 (1987).

[3] H.R. Rezaie, R. Naghizadeh, N. Farrokhnia, S. Arabi, M. Sobhani, Ceramics International 35, 679 (2009).

[4] E. Citak, T. Boyraz, Acta Physica Polonica A 125, 465 (2014).

[5] U. Önen, T. Boyraz, Acta Physica Polonica A $\mathbf{1 2 5}$, 488 (2014).
[6] S.R. Bragança, C.P. Bergmann, Materials Research 8, 39 (2005) 